\title{
Knowing the need for the need to know
}

\section{Niles Eldredge}

The National Museum of Natural History. By Philip Kopper. Pp.493. ISBN 0-8109-1359-3. (Harry N. Abrams: 1982.) $\$ 60, £ 38.50$.

A FEW years ago, when the United States Congress was debating the merits of supporting archaeological salvage work in the valley of the Nubian Nile, a Member of the House of Representatives scornfully suggested that the citizens of the United States had better ways to spend their money than squandering it on the "paleontology of Egypt". Yet Congress has duly undertaken the yearly support of the Smithsonian Institution - a major complex of museums and research stations - ever since the Englishman James Smithson bequeathed his fortune "to found at Washington, under the name Smithsonian Institution, an Establishment for the increase \& diffusion of knowledge among men". Among the array of organizations that have sprung from Smithson's original largesse, Philip Kopper has focused on one: the National Museum of Natural History. He has produced a verbal portrait that, on the whole, nicely augments the quite stunning parade of colour photograhs that both dress this book and themselves have much to say about this particular museum and others of its ilk.

Why, indeed, do we need to know about the "paleontology" of Egypt? For it is this need to know that supplies the ultimate rationale underlying the existence of any natural history museum. There are, of course, other rationalia: some objects are precious, some are beautiful. Some are both: the Hope diamond is one of the National Museum's outstanding treasures. Archaeological pots and Indian bead work have soared in value in recent years - and their beauty, fragility and rarity must all be taken into account. Then, too, museums disseminate information to the world at large, and they entertain: many if not most daily visitors casually peruse an exhibit or two for mere diversion and simple pleasure. Kopper structures his book to embrace all of these diverse functions: the National Museum is a museum of "collections, conservation, science and art" as well as a "public museum". But it is first and foremost a museum of science, as are all its major sister institutions the world over.

Kopper's description of the scientific activities of the National Museum - the final one-third or so of the book - is of necessity rather light, but also somewhat disappointing. In the century following the

- Paul Davies's The Edge of Infinity: Beyond the Black Hole (reviewed in Nature 294,$488 ; 1981$ ) is published today in paperback by Oxford University Press. Price is $£ 2.95$. founding of the major natural history museums, we have seèn the disappearance of cultures, species and many special archaeological and palaeontological sites. Conservation has only recently become all the rage (depressed somewhat by current economic conditions), and it is a blessing indeed that we have had far-sighted collectors filling these museums for so long. But we have also witnessed a return to more holistic (and even hierarchical) approaches to various branches of science. No longer, for example, are molecules the sole objects deemed worthy of serious enquiry in biology as they more nearly were only a decade ago. The contributions of museum scientists to theories of plate tectonics, systematics, biogeography and evolution emphasizes the importance museums have in the scientific world. Kopper, I feel, sees the National Museum too much in isolation; he rightly discusses the achievements of its staff, but robs them of the grander context of the scientific side of the entire academic world.

Yes, natural history museums are treasure troves and libraries of the physical objects of this and other planets. Kopper's book takes a good look at that side of such museums. But the "need to know" transscends curiosity, conservation and the quest for practical application: the urge to understand all aspects of the surrounding world is what has taken us to our present state, for better or worse. We can hardly afford to drop the enterprise now - as, fortunately, a majority of Congressmen seem to perceive.

Niles Eldredge is at the American Museum of Natural History, New York. His most recent book, written with Ian Tattersall, is Myths of Human Evolution (Columbia University Press, 1982).

\section{Nervous disposition}

\section{Jonathan Cooke}

Neuronal Development. Edited by Nicholas C. Spitzer. Pp.424. ISBN 0-306-40956-9. (Plenum: 1982.) £31.50, $\$ 45$.

RECENT decades have seen elucidation of the general strategy of cellular events whereby nervous systems are constructed. Within this framework the search for detailed mechanisms must be made and vast numbers of laboratories now produce parallel stories, using various model systems believed to render one or other part of the developmental sequence especially transparent. Any multi-author work that samples the field, however carefully assembled, has therefore a patchiness about it. It may give us the flavour of current investigations, but is unlikely to serve as a definitive reference work. The present book is no exception.

The first phase of CNS development remains the most mysterious. Accordingly, only two of the contributors claim to address this process in which a spatial pattern of small cell groups, each programmed to give rise solely to one piece of the final structure, arises by positiondependent determinations within one layer of the embryo. One of these chapters is a definitive review but describes an atypical organism, the leech, which utilizes defined cell lineage even for founding the pattern. The other is a tour de force of wilful iconoclasm, claiming to dismiss the established tradition of evidence that the vertebrate CNS pattern arises by positiondependent determinations among a sheet of some 5,000 ectoderm cells in the gastrula, and to implant instead the idea that it is founded from seven small groups of determined precursors set up at early cleavage stages. It certainly makes the critical researcher think, but the presentation is insufficiently balanced or authenticated for a book of this type. The polyclone concept is attractive apart from its truth value, however, and neurobiologists unversed in vertebrate experimental embryology may well, as it were, buy it.

The grasshopper embryo offers a beautiful system in which to study the next phase of development, where detailed local assemblies of neuroblasts are set up, probably by lineage mechanisms. This is reviewed in awesome but exquisite detail by Corey Goodman. A further excellent chapter by Palka lays out the complex but almost coherent story that somatic genetic analysis is revealing, about how the organization of insect ectoderm development by "compartments" is reflected in and utilized by the repetitive pattern of the CNS.

There is much else of interest, about neurite behaviour and the reliable guidance of fibre tracts towards their general target areas, but it is in respect of perhaps the final phase of the strategy - that whereby specific patterns of connections within target areas are assured - that another imbalance in the book occurs. Only the last chapter describes a system known to show such neuronal specificity, among incoming optic fibres to the vertebrate tectum, and here this is treated almost incidentally in what is otherwise a specialized report on anatomical regeneration.

In short, the book does indeed convey a fairly coherent view of what is happening in research into neuronal development, and it includes some fine reviews. But a certain arbitrariness and some omissions of representation are obtrusive.

Jonathan Cooke is a member of the Scientific Staff at the National Institute for Medical Research, Mill Hill, London. 